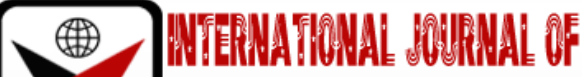 \\ בmRक
}

ISSN 2278-0211 (Online)

\section{Techno-Economic Analysis of Hybrid Small Hydro, Solar PV and Diesel Generator for Itapaji Ekiti, Nigeria}

Olulope P.K
Senior Lecturer, Department of Electrical and Electronic Engineering,
Ekiti State University Ado-Ekiti, Nigeria
Fasina E.T
Lecturer, Department of Electrical and Electronic Engineering,
Ekiti State University Ado-Ekiti, Nigeria
Okafor C.E
Lecturer, Department of Electrical and Electronic Engineering,
Ekiti State University Ado-Ekiti, Nigeria

\begin{abstract}
:
The energy modeling and implementation in Nigeria is solely based on convectional energy system. The system is not sustainable and not environmentally friendly. The abundant of renewable energies in Nigeria are yet to be tapped. This paper presents work done to generate electricity to remote area in Itapaji in Ekiti State. Hybrid system of hydropower, solar PV and nonrenewable diesel generator were used to proposed electricity to the area. The community was selected based on the existing dam in the area.
\end{abstract}

Keywords: Renewable energy, nonrenewable, hybrid systems, small hydropower, solar PV and diesel generator

\section{Introduction}

Sustainable electricity supply does not only support social and economic development processes but also environmental and global climate change management and hence its importance in attainment of standard organization. In the rapidly growing economies of the developing countries the demand for electricity is constantly increasing. Electricity is one of the driving forces in a growing economy and increasing demand puts incredible pressure on the countries' energy infrastructure to match that demand. Developing country like Nigeria, where majority of the population lives in villages with no electricity, the problem assumes greater consideration. Extension of the central electricity grid to such areas is either financially not viable or practically not feasible as these locations are geographically isolated and have a very low power demand. Nigeria is the most populous country in Africa, with a population in excess of 140 million according to the 2006 national census figures. It occupies a total land area of $932,770 \mathrm{~km}^{2}$. About $70 \%$ of the total populations live in the rural areas, while $30 \%$ live in urban centres. The capital city is Abuja, with a population of 1.4 million [1]. Electrification can play an important role to support the economic and social development of an isolated rural society. Demand for electrical energy is increasing while availability of fossil fuels (coal, diesel and petrol) is decreasing [2]. When considering rural electrification, one of the basic questions to be addressed is affordability. Most rural residents especially Itapaji in Ekiti state are low-income earners, with low living standards, limited education and little access to information. The use of hybrid power system has contributed recently and immensely to the development of rural areas.

\section{Research Methodology}

A typical rural area in Itapaji situated in Ikole local government of Ekiti North in Ekiti State, Nigeria has been selected as a study site. The site is situated at $7.62^{\circ}$ North Latitude and $5.22^{\circ}$ Longitude East of Ikole local government. The projected population figure for the community according to the 2006 population census was 5,155 [1]. Electricity requirement of the selected rural site has been established through direct interviewed with the people of the community. The proposed system is projected to supply basic needs such as lighting, communication and domestic motor applications. The reason for this location is because the village has been denied of electricity all through the year. Ele water supply dam, Itapaji-Ekiti, Nigeria was used as a case study. The dam was selected based on its location in a typical rural village. It has a designed capacity of $5,175 \mathrm{~m}^{3} /$ day for the supply of water to thirteen towns and villages in three local government.

\subsection{Data Acquisition}

Primary data were collected through direct interviewed with the people in the study site. The primary data consist of a number of households and population, energy sources, energy consumption patterns, electrical appliances. Individuals with generators have been running the generator with fossil fuel, but have not been in easy mode. The 
interviewed was made with 30 numbers of houses in Itapaji. Dued to unavailability of the villagers, the data was limited to $30 \%$ of the entire data but the data was extrapolated. Out of the representatives from the households that were interviewed, eighteen were women, twelve were men and in the households both men and women participated in the exercise. Most of the households got their living from their gardening and farming and some of them also under trading in buying of farm produce like cassava while some had small shops, restaurants etc. Other noticeable occupations of the people were furniture makers, nurses, a bike mechanic and an owner of a guesthouse. There are about 600 houses in the community. Also, information gotten revealed that the community has been denied of the electricity for the past eight years. Other necessary information was conducted using on-site observation such as counting the number of electrical appliances and lighting devices in each household as shown in Table 2.

\subsection{Working Principle of Small Hydro Power System}

Head refers to the vertical height of the fall of a stream or river. Higher heads provide a greater pressure and therefore greater hydropower potential. As seen from figure 1, the working principle of small hydropower is not different from that of large-scale hydropower. It captures the potential energy of falling water stored in a reservoir to generate electricity. The intake is the opening through which the high-speed moving water finds its way (kinetic energy) to the turbine to rotate the generator that is connected to the consumers' loads. The water turbine, which is of different type depending upon the head and flow rate, converts the energy of falling water into mechanical energy [3]. The generator is house in the power house where the electrical power is being distributed to various users in different locations. The reservoir stored the water to supply appropriate flow rate to the turbine against dry season, since renewable energy is seasonal. The electrical alternator or generator coupled with turbine converts mechanical energy of rotating shaft into electrical energy according to Faradays' law of electromagnetic induction. The amount of electricity produced mainly depends upon the two factors [4]: a) head: the distance that the water falls; b) flow rate: the volume of water that passthrough a given point per second usually measured in meter cube per second.

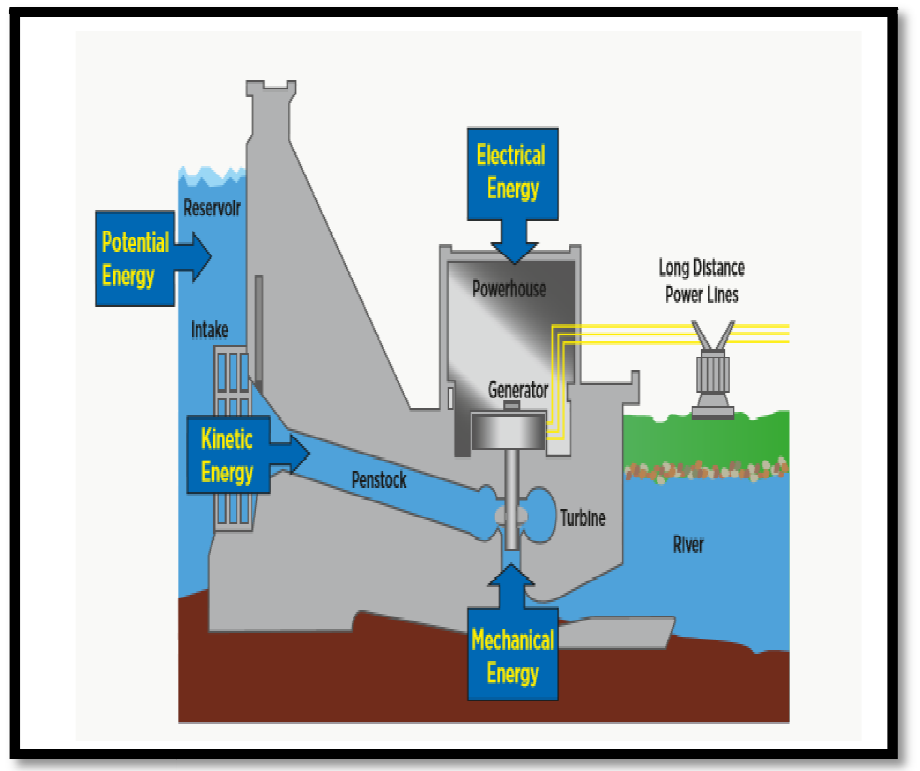

Figure1: Typical 'Low Head' Hydropower Plant with Storage [5]

\subsubsection{PV System}

A photovoltaic system, also PV system or solar power system is a power system designed to supply usable solar power by means of photovoltaic. It consists of an arrangement of several components, including solar panels to absorb and convert sunlight into electricity, a solar inverter/converter to change the electric current from DC to AC, as well as cabling, mounting and other electrical accessories to set up a working system. Solar photovoltaic system or solar power system is one of renewable energy system which uses PV modules to convert sunlight into electricity. The electricity generated can be stored or used directly, fed back into grid line or combined with one or more other electricity generators or more renewable energy source. Solar PV system is very reliable and clean source of electricity that can suit a wide range of applications such as residence, industry, agriculture, livestock, etc. Solar radiation represents the largest energy flow entering the terrestrial ecosystem. After reflection and absorption in the atmosphere, some 100,000TW hit the surface of Earth and undergo conversion to all forms of energy used by humans, with the exception of nuclear, geothermal, and tidal energy. This resource is enormous and corresponds to almost 6,000-fold the current global consumption of primary energy (13.7TW) [6]). Photovoltaic systems currently contribute about 1 percent to worldwide electricity generation [7]. 


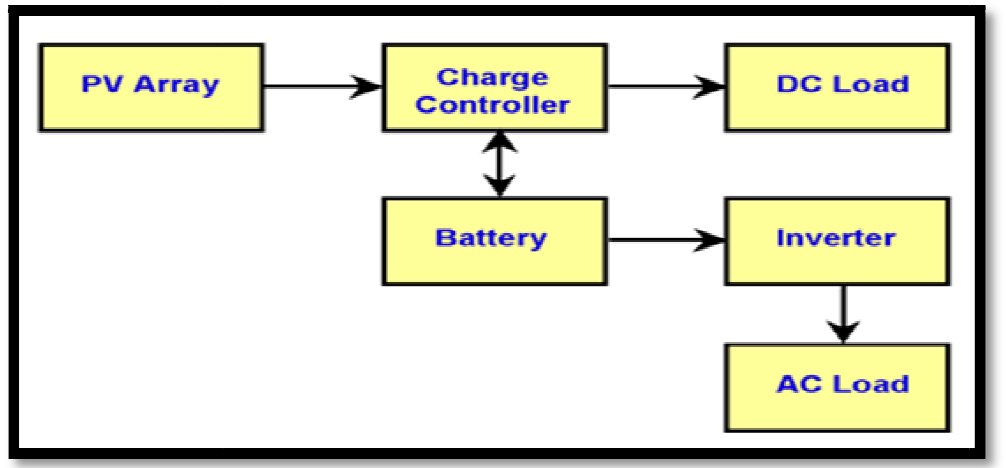

Figure 2: Diagram of stand-alone PV system with Battery Powering DC and AC loads [8]

\subsection{Diesel Generator Model}

Diesel generator (DG) technology is widespread and the development of the power plant is relatively easy. The price of diesel fuel is $200(\$ 0.56 / \mathrm{L})$ based on federal government approved pump price in Nigeria as of November, 2017. The simulated price of diesel fuel was varied from $\$ 0.5$ - $\$ 0.65$ per litre with $\$ 0.5$ which is equal to $\$ 180$ took the best cost of energy. This price varies considerably based on region, transportation costs, and the current market price. The details of the diesel generator model parameters have been given in figure 3. The diesel generator back-up system is operated at times when the output from hydro and solar systems fail to satisfy the targeted load and when the battery storage is depleted. The cost of power per kW used in this DG was based on the current price of the generator in the market.

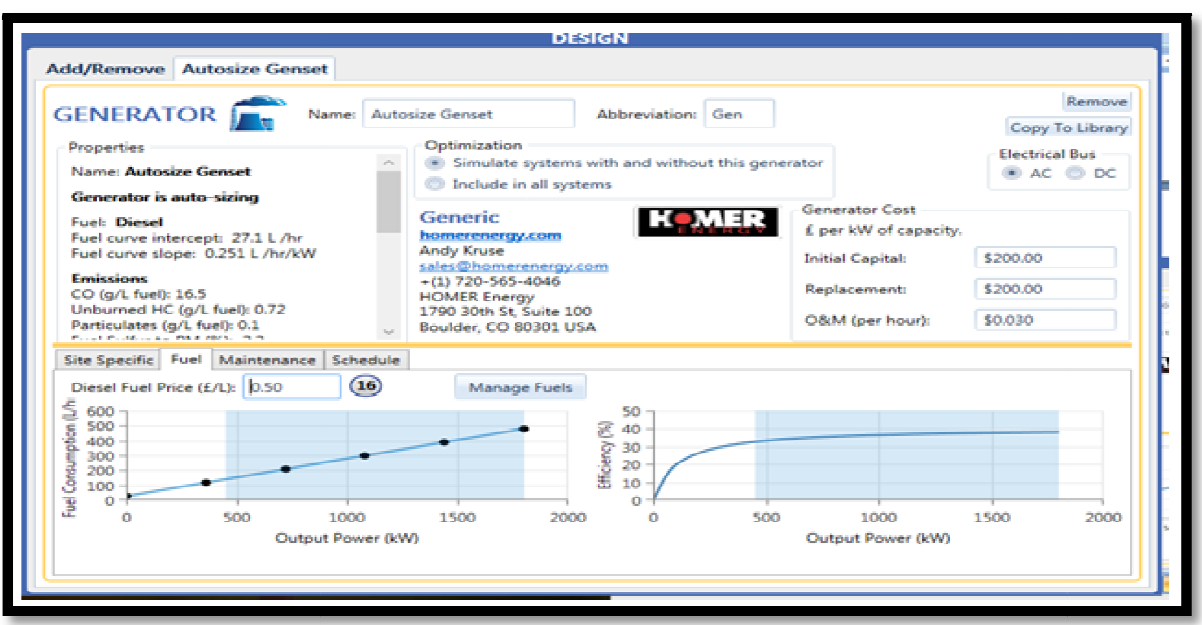

Figure 3: Diesel Input Cost and Graph Model

\subsection{Hybrid System Model}

The HOMER software was designed for hybrid system by placing the appropriate input resource parameters for each individual scheme as shown in Figure 4. After simulation of different type of source of energy which has generated their different energy output. Among the hybrid system are $800 \mathrm{~kW}$ hydropower, $1800 \mathrm{~kW}$ of diesel generator, $200 \mathrm{kWh}$ of battery, $100 \mathrm{~kW}$ of PV and $200 \mathrm{~kW}$ of converter.

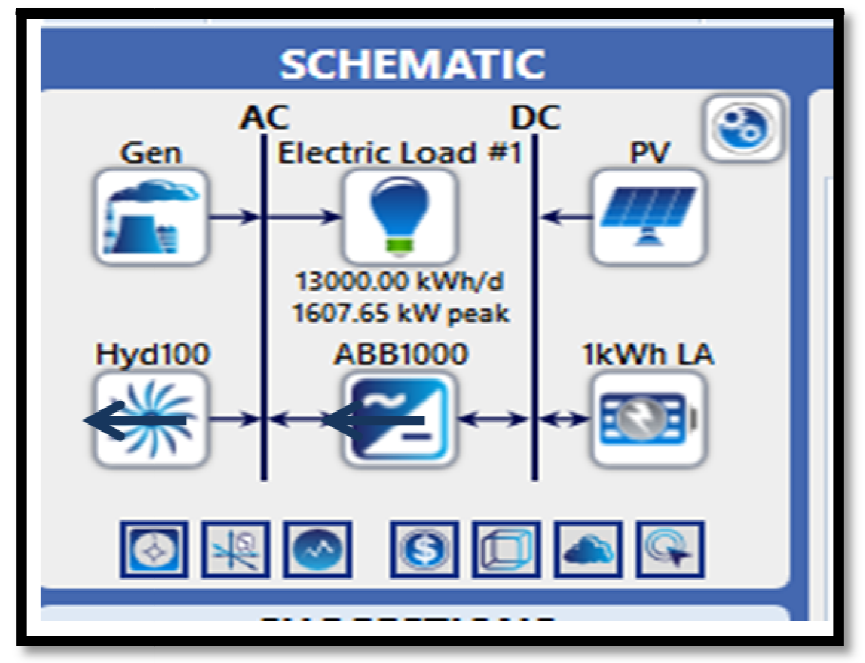

Figure 4: Modeling of the Proposed Hybrid System 


\begin{tabular}{|lll|}
\hline S/N & Parameter & Value \\
\hline 1 & Average annual maximum discharge & $23.24 \mathrm{~m}^{3} / \mathrm{s}$ \\
2 & Average annual minimum discharge & $1.78 \mathrm{~m} / \mathrm{s}$ \\
3 & Mean discharge & $8.33 \mathrm{~m}^{3} / \mathrm{s}$ \\
4 & Hydraulic loss & $4 \%$ of Gross Head $(0.9 \mathrm{~m})$ \\
5 & Net head, Hn & $21.6 \mathrm{~m}$ \\
6 & Gross head, Hg & $22.5 \mathrm{~m}$ \\
7 & Residual flow & $4.33 \mathrm{~m}^{3} / \mathrm{s}$ \\
8 & Total Efficiencies & 0.73 \\
9 & Acceleration due to gravity, g & $9.81 \mathrm{~m}^{2} / \mathrm{s}$ \\
\hline
\end{tabular}

Table 1: Site Conditions and Hydro Power Parameters for Ele Dam at Itapaji, Nigeria [9]

\begin{tabular}{|l|l|l|l|l|l|}
\hline S/N & APPLIANCES & MINIMUM/MAXIMUM & NO. & ENERGY PER DAY & \\
\hline 1 & $60 \mathrm{~W}$ light bulb & $60 \mathrm{~W} / 60 \mathrm{~W}$ & 6 & $360 \times 12=720$ \\
2 & TV $(19 "$ colour & $70 \mathrm{~W} / 100 \mathrm{~W}$ & 1 & $100 \times 8=800$ \\
3 & Electric Kettle & 200W/200W & 1 & $200 \times 6=1200$ \\
4 & Electric Iron & $1000 \mathrm{~W} / 1000 \mathrm{~W}$ & 1 & $1000 \times 6=6000$ \\
5 & Table Fan & $10 \mathrm{~W} / 50 \mathrm{~W}$ & 1 & $50 \times 10=300$ \\
6 & Radio & $20 \mathrm{~W} / 20 \mathrm{~W}$ & 1 & $20 \times 10=200$ \\
7 & Small phone & $5 \mathrm{~W}$ & 600 & $3000 \times 6=18000$ & \\
& & & & $\mathbf{3 0 . 3 k W h}$ & \\
& TOTAL & & & & \\
\hline
\end{tabular}

Table 2: List of the Power Consumption of Typical Household Appliances in Itapaji

\subsection{Estimated Load of the Community}

$\mathrm{E}=\operatorname{Prtn}$

(1)

Where Pr is the wattage rating of a given household appliance (component) in kilowatt (kW), $t$ is the duration for which the appliance is to be operated in hours $(\mathrm{h}), \mathrm{n}$ is the number of the appliance.

The energy demand estimates has been expressed in $\mathrm{kWh}$, because it is fundamental unit in which quantity of electricity (electric energy) used is measured. One kilowatt-hour is equivalent to the amount of work done by one kilowatt of electric power in one hour. A family could accommodate all these uses daily within a consumption range of $30.3 \mathrm{kWh}$ daily.

Now, to calculate the load use per day, a diversity factor of 0.7 is used because all cannot be $\mathrm{ON}$ at the same time for all the houses in Itapaji.

$30.3 \mathrm{kWh} \times 0.7=21.21 \mathrm{kWh}$ per day

600 houses in Itapaji will therefore have a daily energy of,

$21.21 \mathrm{kWh} \times 600=13000 \mathrm{kWh}$

Daily Power $=13000 / 24=542 \mathrm{~kW}$

\subsection{Calculating the Forecast Load Demand of Itapaji to 2025}

The estimated load of Itapaji community at present is $542 \mathrm{~kW}$ with 5,155 people according to 2006 census [1] which will increase with increase in population. Therefore, the load estimated for 2025 with a forecasted population of about 7500 people is calculated below.

Load per one population $=542000 / 5155=0.105 \mathrm{~kW} /$ people

Load for 7500 people $=0.105 \mathrm{~kW} /$ people $\times 7500$ people $=787.5 \mathrm{~kW}$

Estimated load of the community by 2025 is approximately $=788 \mathrm{~kW}$.

Estimated increase in load by $2025=(788-542) \mathrm{kW}=246 \mathrm{~kW}$

Therefore, design of the Itapaji power station planning must be design in such a way to cater for these forecast load.

\subsection{Estimated Load Demand and the Hydro Power Potential of the Dam}

The estimated power demand by the village as at November, 2017 is $542 \mathrm{~kW}$. The hydro turbines generate 206.1 $\mathrm{kW}$ at minimum discharge during dry season. The power deficit is $(542-206.1) \mathrm{kW}=336 \mathrm{~kW}$. Consequently, there is need to complement the hydro power source with another renewable energy-Solar PV. Hence, there's need for small hydro power plant-based hybrid system.

$\mathrm{P}=\mathrm{Q} \times \mathrm{H} \times \mathrm{g} \times \eta$

Where $\mathrm{P}$ is power output in $\mathrm{kW}, \mathrm{Q}$ is turbine flow in $\mathrm{m} 3 / \mathrm{sec}, \mathrm{H}$ is net head in meter (elevation between intake at the river and out late at the turbine less head loss along the power channel), $g$ is acceleration due to gravity which value is equal to $9.81 \mathrm{~m} / \mathrm{sec} 2$, and $\eta$ is overall efficiency of the system. 


\begin{tabular}{|c|c|c|c|}
\hline Month & $\begin{array}{c}\text { Solar irradiance } \\
\left(\mathbf{k W} / \mathbf{m}^{\mathbf{2}} \mathbf{)}\right.\end{array}$ & $\begin{array}{c}\text { Peak sunshine } \\
\text { hour }\end{array}$ & $\begin{array}{c}\text { Temperature (o } \\
\mathbf{C})\end{array}$ \\
\hline January & 0.6121 & 7.01 & 26.0 \\
February & 0.5798 & 7.81 & 28.1 \\
March & 0.5797 & 6.60 & 28.3 \\
April & 0.4985 & 6.12 & 28.1 \\
May & 0.4855 & 6.21 & 27.0 \\
June & 0.4363 & 6.12 & 25.5 \\
July & 0.3822 & 6.41 & 24.5 \\
August & 0.3565 & 6.61 & 24.5 \\
September & 0.3822 & 3.71 & 24.6 \\
October & 0.4509 & 5.81 & 25.6 \\
November & 0.5633 & 7.31 & 26.2 \\
December & 0.6132 & 5.11 & 25.7 \\
\hline
\end{tabular}

Table 3: Average Monthly Climatic Data [9]

The equation below shows the power to be generated

$\operatorname{Ppv}=\eta A p N p v E(t)$

Where $\eta, A p, N p v$ and $E(t)$ are the energy conversion efficiency (\%), the area of single PV panels, the number of PV panels and the insolation data respectively. The power deficit by hydropower system is $336 \mathrm{~kW}$, so, this power must be complemented by the solar PV in order to meet the demand load of the targeted community.

\section{Results and Discussions}

\subsection{Economic Analysis of the Software}

Economic indices determine the life cycle economic of the system. Of the particular interest is the total net present cost (NPC). This information, in turn enables the optimum renewable energy component sizes that would be required to meet the specific fraction of the load at the least cost. As HOMER calculate in US Dollar (\$), all costs have been converted from Nigeria naira (\$) to USD (\$), using the equivalent as 1US Dollar (\$) equal to \$360 of Nigerian currency. Afterwards, the calculation has been performed, the HOMER calculated all output in US Dollar (\$). The US Dollar was converted to naira where necessary.

\subsection{Hybrid System Simulation with Hydro Resource}

The capital cost is $(\$ 1,304,711.50)$ and the operating cost is $(\$ 400,214.50)$ compared to the simulation without hydro resource. The cost of energy, COE is $\$ 0.2750 / \mathrm{kWh}$ with diesel consumption of $1,336,395$ litres per annum when the generator was connected. The percentage contribution of each of the power generation is as shown in Table 4 below.

\begin{tabular}{|l|l|l|}
\hline Production & $\mathrm{kW} / \mathrm{h} / \mathrm{yr}$ & $\%$ \\
\hline Generic flat plate PV & 14,430 & 0.177 \\
\hline Autosize Genset & $4,533,132$ & 55.7 \\
Hydro & $3,595,375$ & 44.2 \\
Total & $8,142,938$ & 100 \\
\hline
\end{tabular}

Table 4: Percentage Contribution of Each of the Generation in the Hybrid System with Hydro

\subsection{Hybrid System Simulation without Hydro Resource}

The capital cost $(\$ 1,537,646.47)$ is higher than the cost of hybrid with hydro and the operating cost $(\$ 474,860.50)$ is very high due to high consumption of diesel. The cost of energy (COE) is $\$ 0.324 / \mathrm{kwh}$ with diesel consumption of $1,603,409$ litres per annum. The percentage contribution of each of the generation is as shown in Table 5 below.

\begin{tabular}{|l|l|l|}
\hline Production & kW/h/yr & $\%$ \\
\hline Generic flat plate PV & 14,430 & 0.265 \\
\cline { 1 - 2 } Autosize Genset & $5,438,120$ & 99.7 \\
Totall & $5,452,550$ & 100 \\
\hline
\end{tabular}

Table 5: Percentage Contribution of the Generation of the Hybrid System without Hydro 


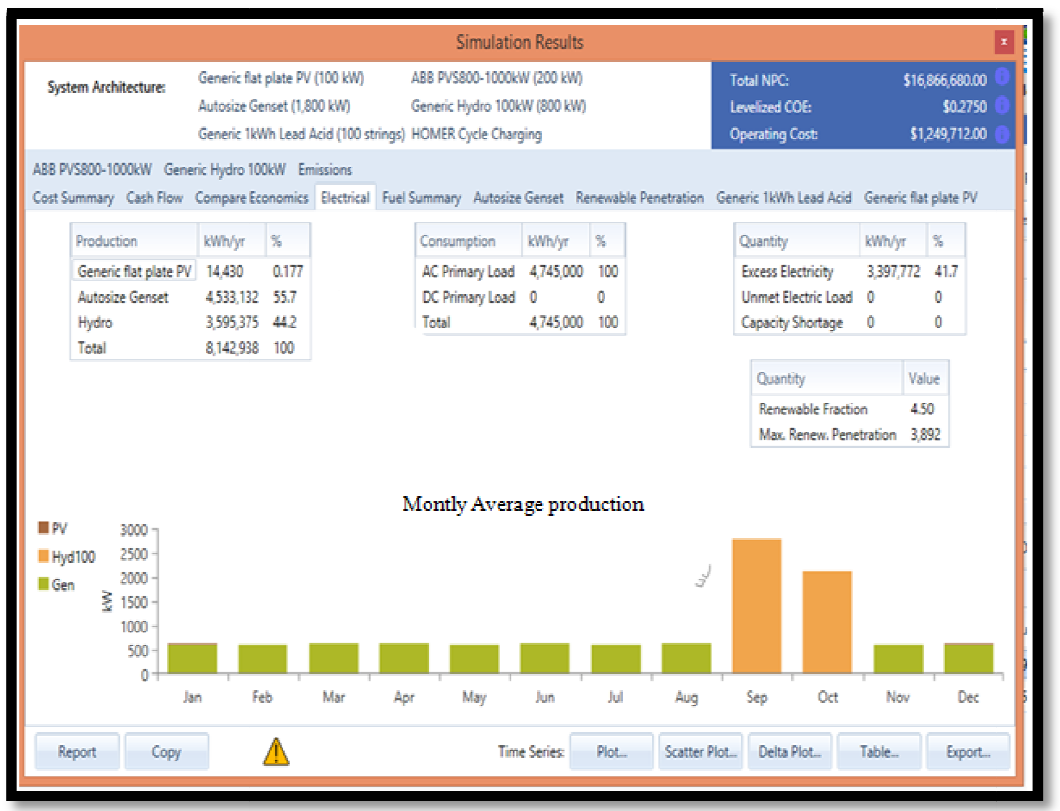

Figure 5: Electrical Production Output with Hydro

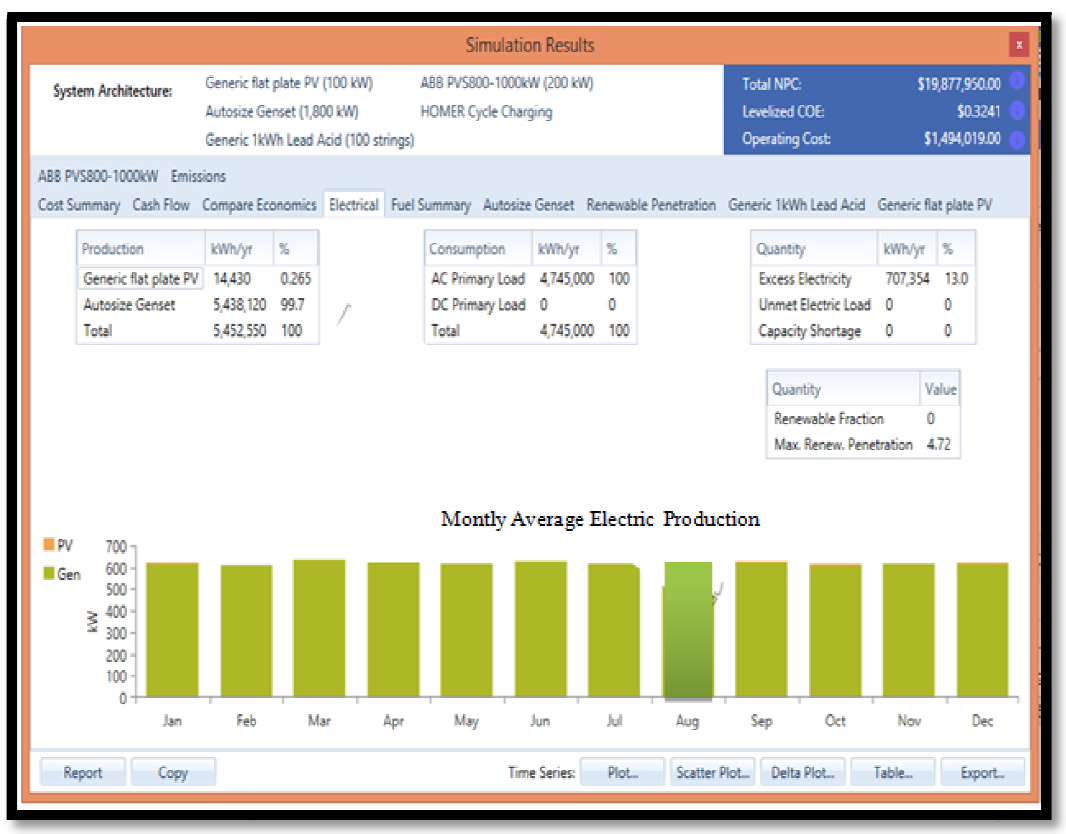

Figure 6: Electrical Production Output without Hydro

As seen from figure 5 above, the energy generated from the hybrid system (Solar PV, Diesel Generator and Hydropower) is $8,142,938 \mathrm{kWh} / \mathrm{yr}$. The total power generated is $930 \mathrm{~kW}$, since the load of the community is $542 \mathrm{~kW}$.

(930-542) $\mathrm{kW}=388 \mathrm{~kW}$. Excess power.

The excess power supply caters for load forecasted of $246 \mathrm{~kW}$ and losses in the system.

\subsection{Technical Analysis of the System}

Various components of hybrid system of hydropower, solar PV and diesel generator has been used in this research work with HOMER software simulating and optimizing the best cost of energy by comparing the three different generating station used. The components used for this hybrid are Generic flat plate PV $(100 \mathrm{~kW})$, converter ABB1000 (200kW), Autosize genset $(1800 \mathrm{~kW})$, Generic hydro $(800 \mathrm{~kW})$ and Generic $1 \mathrm{kWh}$ lead acid $(200 \mathrm{~kW})$. All these components already exist. One just needs to purchase from reliable source or from designated manufacturer. Although, improvement should be made on the design of diesel generator to enhance its efficiency and other components of the system like battery. Therefore, from technological viewpoint, the project is feasible to construct and to implement.

\subsection{Economic analysis of the Proposed Hybrid System}

As analysed earlier, the cost of energy (COE) of each generation components with hydropower have been thoroughly dealt with, hence, on the final cost of energy simulated by the HOMER software with cost of energy $\mathrm{N} 99 / \mathrm{kWh}$. The total energy generated by these generators is $8,142,938 \mathrm{kWh} / \mathrm{yr}$ multiply by cost of energy (COE), the result is $\$ 2,239,308$.

Also, total cost of energy per annum minus total cost of generations 


\section{$(8,142,938 \times 0.2750)-(1,304,711.50)=\$ 934,597$}

By converting $\$ 0.2750$ to naira, we have, $0.2750 \times 360=\$ 99$

Also, on the side of economic viewpoint, the project is feasible, although, the cost of energy simulated by the HOMER software seems high, I hope with further reduction of the price of diesel per litre and with design improvement with reduction in components cost, the cost of the energy per kWh will further reduced. The lifetime of hydropower was estimated to be 25years, PV solar system was estimated to be 20years, battery lifetime 5years, converter 10years, controller 20years and generator was estimated to be 5years. The energy generated annually was found to be $8,142,938 \mathrm{kWh}$ as compared with simulation without hydropower with annual energy generated of 5,452,550.00kWh and cost of energy (COE) of $\$ 0.3248$.

\section{Conclusion}

Hybrid power generation comes into existence due to high price of generating power from oil and distance of power grid from rural areas, also due to the limited availability of such kind of non-renewable sources. HOMER software can sensitive and optimize the power supply especially in an off-grid rural area. However, it is still considered expensive and difficult to combine various energy sources together. The expense is only for one time with a life span of about 2025years. So, it can easily be considered. The simulated hybrid system for Itapaji dam can be used to power the targeted community and the nearby rural areas which in turn increase the socio-economic of the nation at large. Hybrid Optimization Model for Electric Renewable (HOMER) was used to simulate and generate feasible solution through combinations of photovoltaic, hydro- turbines and diesel generators with a minimum cost of electricity. The simulations indicated that a hybrid system with hydro is more feasible to the village of study as compared to the simulation without hydro; hence there is possibility of utilizing renewable power to reduce the dependence on fossil fuel for power generation in order to meet the energy requirement and at minimum cost of energy. The Hybrid power system (PV, Hydro, Diesel generator and battery) has the maximum renewable energy penetration by supplying $99 \%$ of the energy demand. It has total NPC of $\$ 16,866,679.54$ at $\$ 99 / \mathrm{kWh}$ and emits $3,498,168 \mathrm{Kg} / \mathrm{yr}$ of CO2 into the atmosphere. This system has the ability to reduce the proportion of energy supply by diesel generator. The hybrid power system with hydro offers a better performance to provide power supply than the one without hydro. The simulation results demonstrate that utilizing renewable and nonrenewable generators such as hybrid (PV, hydro, diesel generator and battery) reduces the operating costs; greenhouse gases (CO2) and less fuel consumption and a major positive contribution of this study is the evaluation of the savings and the reduction in the quantity of different air pollutants.

Most energy technologies suffer from an intermittent characteristic due to the own diurnal and seasonal patterns of the natural resources needed for power generation, hence, a complementary energy storage system must be considered. Furthermore, improvement should be made to the HOMER software in order to directly input the calculated power value which result in reduction of utilization of the fossil fuel that pollutes the environment. Efficiency of diesel generator should be improved through design in order to reduce fuel consumption and to deliver output power at greater efficiency. Also, design of other components like battery and solar panel should be improved as well to deliver at higher efficiency as the efficiency of the battery seems low. Government should made substantial amount of money available for all final year engineering students to assist them to carry out their project, since engineering profession is a pivot for national development. Finally, the software should be made available everywhere for researchers at cheaper rate, because difficulties were encountered before the software was gotten, also the cost of the software should be reduced.

\section{References}

i. NPC: National Population Commission Census, 2006. Official Website of National Population Commission, Abuja, 2007.

ii. Ministry of Economic Affairs, Agriculture and Innovation, (Accessed March 08, 2011) Available at: http://www.government.nl/documents-and-publications/reports/2011/11/01/energy report-2011. Html. 2008.

iii. O. Paish, 'Small hydro power: technology and current status', Renewable and Sustainable Energy Reviews, vol. 6, no. 6, pp. 537-556, 2002. View at Publisher • View at Google Scholar.

iv. A.Omojolaa, O.A. Oladejibe, 'Small hydro power for rural electrification in Nigeria,' American Journal of Science and Engineering, vol. 1, no. 2, 2012. View at Google Scholar

v. Victor Kaplan, 'New Austrian Stamps', 24 January 1937.

vi. IEA, 'World Energy Outlook 2004', International Energy Agency, Paris, IEA/OECD, 2004.

vii. Tam Hunt 'The Solar Singularity Is Nigh'. Greentech Media. 9 March 2015.http:// wikipedia.com

viii. G. A. Adepoju and B. Adebanji, 'Feasibility Study and Optimal Design of Small Hydropower-photovoltaic-diesel Generator Hybrid Power System for Itapaji-Ekiti, Nigeria,' Article no.JSRR.26706 ISSN: 2320-0227, Journal of Scientific Research \& Reports 11(2): pp. 1-10, 2016. 